\title{
Systemic and Intra-Amygdala Administration of Glucocorticoid Agonist and Antagonist Modulate Extinction of Conditioned Fear
}

\author{
Yi-Ling Yang', Po-Kuan Chao' and Kwok-Tung Lu*,2 \\ 'Department of Molecular Biology and Biochemistry, Institute of Biotechnology, National Chia-Yi University, Chia-Yi, Taiwan; ${ }^{2}$ Department of Life \\ Science, National Taiwan Normal University, Taipei, Taiwan
}

\begin{abstract}
We examined the effect of glucocorticoid agonists on the extinction of conditioned fear in rats by using fear-potentiated startle. Systemic injection of glucocorticoid receptor agonists dexamethasone (DEX) $(0.1,0.5$, and $1.0 \mathrm{mg} / \mathrm{kg})$ and intra-amygdala infusion of RU28362 $(0.5,1.0$, and $3.0 \mathrm{ng} / \mathrm{side})$ prior to extinction training facilitated extinction of conditioned fear in a dose-dependent manner. Extinction of conditioned fear and circulating corticosterone levels were attenuated by administration of corticosteroid synthesis inhibitor metyrapone (25 mg/kg s.c.) 90 min before extinction training. The facilitation effect of DEX was dependent on repeated presentation of the conditioned stimulus rather than exposure to the experimental context, indicating this effect did not result from impaired expression of conditioned fear or accelerated forgetting. Intra-amygdaloid administration of the glucocorticoid receptor antagonist mifepristone (0.I, 0.2 , and $0.5 \mathrm{ng} / \mathrm{side}$, bilaterally) blocked extinction of conditioned fear and the facilitation effect of DEX in a dose-dependent manner. Mifepristone ( $2 \mathrm{ng} / \mathrm{side}$ ) did not affect extinction but blocked the facilitating effect of DEX. Systemic administration of DEX after extinction training also facilitated extinction, suggesting that DEX may influence the memory consodilation phase of extinction. The Dose of dexamethsone or metyrapone used here did not influence fear-potentiated startle when administered before testing. Thus, it is unlikely that these drugs influenced extinction by increasing or disrupting CS processing. All results suggested that amygdaloid glucocorticoid receptors were involved in the extinction of conditioned fear.
\end{abstract}

Neuropsychopharmacology (2006) 31, 912-924. doi: 10.1038/sj.npp. 1300899; published online 5 October 2005

Keywords: glucocorticoid; amygdala; extinction; conditioned fear

\section{INTRODUCTION}

A large literature indicates that glucocorticoid plays an essential role in the formation of fear memory. Corticosterone levels after conditioning were correlated with fear conditioning levels (Cordero et al, 1998). Adrenalectomy can reduce the unconditioned freezing behavior of the newborn mice (Takahashi, 1994a,b). Administration of corticosteroid synthesis inhibitor increases the time animals spend on the open arm area of an elevated plusmaze (Roozendaal et al, 1996). Similar results can also be obtained by intracerebroventricle administration of glucocorticoid receptor antagonist (Korte et al, 1995) or intrahippocampal administration of mineralocorticoid receptor antagonist (Bitran et al, 1998). Systemic adminis-

*Correspondence: Dr K-T Lu, Department of Life Science, National Taiwan Normal University, 88 Ting-Chow Rd, Sec 4, Taipei, Taiwan, Tel: + 886229333149 ext 234, fax: 886229312904 ,

E-mail: ktlu@ntnu.edu.tw

Received 19 January 2005; revised 8 August 2005; accepted 10 August 2005

Online publication: 18 August 2005 at http://www.acnp.org/citations/ Npp08 $1805050043 /$ default.pdf tration of glucocorticoid synthesis inhibitor metyrapone attenuated long-term expression of contextual fear conditioning in a dose-dependent manner (Cordero et al, 2002). In addition, intraperitoneal injection of metyrapone (Baez and Volosin, 1994) or intrahippocampal injection of antisense targeting the glucocorticoid receptor mRNA in the dentate gyrus of the hippocampus (Korte et al, 1995) eliminates the animal's learned immobility in the Porsolt forced swim test. Intracerebroventricle administration of glucocorticoid receptor antagonist RU38486 inhibited fear conditioning (Pugh et al, 1997a,b; Cordero and Sandi, 1998). All this evidence suggests that glucocorticoid is critically involved in the formation of fear memory.

Glucocorticoid also participates in the consolidation, retrieval, and extinction of conditioned fear (Roozendaal et al, 2002; Roozendaal, 2003). Adrenalectomy blocks extinction of passive avoidance. Subcutaneous or intracerebroventricle administration of corticosterone normalizes the extinction of avoidance behavior in adrenalectomized rats (Bohus et al, 1982). Barrett and Gonzalez-Lima (2004) reported that administration of corticosterone inhibitor impairs extinction of conditioned freezing. 
Extinction is defined as a reduction in conditioned fear when the conditioned stimulus is repeatedly presented in the absence of the unconditioned stimulus. Many studies demonstrate that extinction is not only the result of forgetting or ofmemory erasure but also involves the formation of new associations that compete with prior fear-conditioned associations (Davis, 2000; Davis et al, 2000; Rescorla, 2001; Bouton, 2002; Myers and Davis, 2002; Delamater, 2004). The inability to extinguish intense fear memories is an important clinical problem in psychiatric disorders distinguished by a dysregulation of fear, such as specific phobia, panic disorder, and post-traumatic stress disorder (PTSD) (Morgan et al, 1995; Fyer, 1998; Gorman et al, 2000). Treatment for these disorders often relies on the progressive extinction of fear memories (Zarate and Agras, 1994; Dadds et al, 1997; Foa, 2000). Recent clinical studies showed that PTSD patients often appear with reduced cortisol level (Yehuda et al, 2004) and daily cortisol administration reduced symptoms of traumatic memory in PTSD patients (Aerni et al, 2004). These results suggest that brain glucocorticoid is involved in the dysregulation of fear memory extinction. Recent studies indicate that several brain structures are involved in the extinction of conditioned fear that includes the basolateral nucleus of the amygdala (Davis and Whalen, 2001; Maren, 2001) and dorsal hippocampus (LeDoux, 2002; Barrett et al, 2003). Glucocorticoid receptors are also located in those brain structures (Fuxe et al, 1985; Van Eekelen et al, 1987; Korte, $2001)$. It raised the possibility that amygdaloid glucocorticoid receptors are involved in the extinction of conditioned fear. Clarifying the role of glucocorticoid in the extinction process may be very useful in the treatment of psychiatric disorders involving dysregulated fear responses. The present study was aimed at examining the possible effect of systemic and intra-amygdaloid administration of glucocorticoid agonists on the extinction of conditioned fear by using a fear-potentiated startle paradigm.

\section{MATERIALS AND METHODS}

\section{Animals}

Adult male Sprague-Dawley rats (obtained from the animal center of National Taiwan University) weighing between 250 and $350 \mathrm{~g}$ were used. Animals were housed in groups of four rats in a temperature $\left(24^{\circ} \mathrm{C}\right)$-controlled animal colony, with continuous access to food and water. Rats were kept on a $12: 12$ light-dark cycle with lights on at 0700 . All behavioral procedures took place during the light cycle. All procedures were conducted in accordance with the National Institutes of Health Guide for Care and Use of Laboratory Animals and the guidelines set forth by the Institutional Animal Care and Use Committee at the National Taiwan Normal University.

\section{Surgery}

All surgeries were carried out under sodium pentobarbital $(50 \mathrm{mg} / \mathrm{kg}$ i.p.) anesthesia. Once anesthetized, the rat was placed in a Kopf stereotaxic instrument, the skull was exposed, and 22-gauge guide cannula (model C313G, Plastic-one Products, Roanoke, VA) were implanted bilat- erally into the basolateral nucleus of the amygdala (BLA) (AP, -2.8; DV, -7.0, ML, \pm 5.0 from bregma, Paxinos and Watson, 1997). Size 0 insect pins (Carolina Biological Supply, Burlington, NC) were inserted into each cannula to prevent clogging. These extended about $2 \mathrm{~mm}$ past the end of the guide cannula. Screws were anchored to the skull and the assembly was cemented in place using dental cement (Plastic-one Products, Roanoke, VA). Rats received an antibiotic (penicillin) once every day for the first 3 days after the surgery to reduce the risk of infection.

\section{Behavioral Procedures}

Extinction of the conditioned fear was measured using the potentiated startle paradigm (Cassella and Davis, 1986; Lu et al, 2001, Walker et al, 2002). Rats were trained and tested in a startle chamber (San Diego Instruments, San Diego, CA). Each chamber consisted of an $8.6-\mathrm{cm}$ diameter, $20-\mathrm{cm}$ long Plexiglas cylinder mounted on a Plexiglas base. A grid floor insert made of seven 4-mm diameter stainless-steel bars placed $4 \mathrm{~mm}$ apart was mounted inside the Plexiglas cylinder to deliver footshocks. The delivery of the acoustic stimulus, light, and footshock, and the measurement of the startle response were controlled by computer. The cage movement results in the displacement of an accelerometer. Startle amplitude was defined as peak accelerometer voltage within $200 \mathrm{~ms}$ after startle stimulus onset.

The behavioral procedures common to all experiments consisted of an acclimation phase, a baseline startle test phase, a fear-conditioning phase, a pre-extinction test, an extinction training, and a postextinction test (see Figures $1 \mathrm{a}, 3 \mathrm{a}$, and $4 \mathrm{a})$.

Acclimation: On each of 3 consecutive days, rats were placed into the test chambers for $10 \mathrm{~min}$ and then returned to their home cages.

Baseline startle test: On each of the next 2 consecutive days, animals were placed in the test chambers and presented with thirty $95-\mathrm{dB}$ startle stimuli at a 30-s interstimulus interval (ISI). Animals whose baseline startle was $<1 \%$ of the measurable level were not included in later analyses.

Fear conditioning: After $24 \mathrm{~h}$, rats were returned to the test chambers and $5 \mathrm{~min}$ later given the first of 10 lightfootshock pairings. The shock (unconditioned stimulus) was delivered during the last $0.5 \mathrm{~s}$ of the $3.7 \mathrm{~s}$ light (conditioned stimulus). The average intertrial interval was $4 \mathrm{~min}$ (range $=3-5 \mathrm{~min}$ ) and the shock intensity was $0.6 \mathrm{~mA}$.

Pre-extinction test: At $24 \mathrm{~h}$ after fear conditioning, rats were returned to the test chambers and $5 \mathrm{~min}$ later presented with 30 startle-eliciting noise bursts $(95 \mathrm{~dB}-30 \mathrm{~s}$ ISI). These initial startle stimuli were used to habituate the startle response to a stable baseline prior to the lightnoise test trials that followed. After $30 \mathrm{~s}$ a total of 20 startle-eliciting noise bursts were presented, 10 in darkness (noise alone) and ten $3.2 \mathrm{~s}$ after onset of the $3.7 \mathrm{~s}$ light (light-noise) in a balanced, irregular order at a 30 -s ISI. Percent fear-potentiated startle was computed as ((startle amplitude on light-noise minus noise-alone trials)/noisealone trials) $\times 100$. Based on these data, the rats were divided into equal size groups that had comparable mean levels of percent fear-potentiated startle. Animals with less 
than $50 \%$ fear-potentiated startles during the pre-extinction test were not used.

Extinction training: Extinction training (cue exposure) is defined as the repetitive exposure to the conditioned stimulus cue (light) in the absence of the unconditioned stimulus. At $24 \mathrm{~h}$ after the pre-extinction test, rats were returned to the test chamber and $5 \mathrm{~min}$ later presented with thirty 3.7-s light exposures at a 30-s ISI. Context control groups (context exposure) remained in the test cages for the same amount of time but did not receive light presentations. Extinction training was performed for varying numbers of consecutive days as described below.

Postextinction test-1: At $24 \mathrm{~h}$ after the last extinction training period, rats were returned to the test chamber and 5 min later presented with thirty $95-\mathrm{dB}$ leader stimuli for a habituated startle baseline. This was followed by a total of 60 startle-eliciting noise bursts, 30 in darkness (noise alone) and 30 presented $3.2 \mathrm{~s}$ after onset of the $3.7 \mathrm{~s}$ light (lightnoise) in a balanced, irregular order at a 30-s ISI. Results were evaluated as with the pre-extinction test.

Postextinction test-2: At $24 \mathrm{~h}$ after the extended extinction training period, rats were returned to the test chamber for the postextinction test described above.

Fear-potentiated startle test: At $24 \mathrm{~h}$ after the fear conditioning, rats were returned to the test chamber and testing for the fear-potentiated startle (procedure is similar to the postextinction test-1 described above).

\section{Drug Treatment}

Dexamethasone (DEX, Sigma, St Louis, MO, USA) was freshly dissolved in saline. The $0.1,0.5$, or $1.0 \mathrm{mg} / \mathrm{kg}$ DEX was injected intraperitoneally $15 \mathrm{~min}$ prior to extinction training with a 26-gauge injection needle connected to a $1 \mathrm{ml}$ syringe. RU28362 (0.5, 1.0 , or $3.0 \mathrm{ng} / \mathrm{side}$, dissolved in $20 \%$ DMSO, Roussel-Uclaf, Romainville, France) was infused into the BLA $30 \mathrm{~min}$ prior to extinction training. Injections were made through 28-gauge injection cannulas (model C313I, Plastic Products) that were connected to a Hamilton microsyringe via polyethylene tubing. The infusion speed was $0.25 \mu \mathrm{l} / \mathrm{min}$. The total volume of injection was $0.8 \mu \mathrm{l}$ per side. Metyrapone (MET, $25 \mathrm{mg} / \mathrm{kg}$ s.c.) was given $90 \mathrm{~min}$ prior to a single session of extinction training for a total of 2 days extinction training. Glucocorticoid receptor antagonist mifepristone (RU38486, Sigma, St Louis, MO, USA) was dissolved in 20\% DMSO and administrated into the basolateral nucleus of the amygdala $(0.1,0.2$, or $0.5 \mathrm{ng} / \mathrm{side}$, bilaterally) $10 \mathrm{~min}$ prior to a single session of extinction training.

\section{Histological Assessment}

Upon completion of the experiment, animals were overdosed with sodium pentobarbital and perfused through the heart with PBS followed by $10 \%$ formaldehyde. Brains were sectioned $(40 \mu \mathrm{m})$ and stained with cresyl violet to assess infusion site.

\section{Immunoassay for Corticosterone}

Animals were overdosed with sodium pentobarbital. They were decapitated $90 \mathrm{~min}$ after the second injection of metyrapone. Trunk blood was collected in heparinized $(500 \mathrm{U} / \mathrm{ml})$ tubes and stored on ice. After centrifuging at $4500 \mathrm{~g}$ for $10 \mathrm{~min}$, the supernatant was stored at $-80^{\circ} \mathrm{C}$ until assay. Corticosterone plasma concentration was determined by a commercially available enzyme immunoassay kit using a 96-well microtiter plate coated with polyclonal antibody raised against corticosterone (Alpco, Windham, NH). Absorbance levels were measured with a photometric microplate reader at $450 \mathrm{~nm}$. Sensitivity was $0.023 \mathrm{mg} / \mathrm{dl}$. Coefficients of variation within and between assays were $<10 \%$.

\section{Statistics}

ANOVA on percent potentiation scores was the primary statistic. Between-group comparisons were also made using two-tailed $t$-tests for independent samples. The criterion for significance for all comparisons was $p<0.05$.

\section{RESULTS}

\section{Experiment 1: Systemic Administration of Glucocorticoid Receptor Agonist DEX Facilitated Extinction of Conditioned Fear}

This experiment assessed the effect of the synthetic glucocorticoid receptor agonist DEX on the extinction of conditioned fear. Initially, 38 rats were used. Six were excluded for showing $<50 \%$ fear-potentiated startle during the pre-extinction test. The final 32 rats were assigned into four different groups of eight animals based on their level of fear-potentiated startle in the pre-extinction test. At $24 \mathrm{~h}$ after the pre-extinction test, they received one of the following treatments: saline (control group), $0.1 \mathrm{mg} / \mathrm{kg}$ DEX (low-dose group), $0.5 \mathrm{mg} / \mathrm{kg}$ DEX (medium-dose group), and $1.0 \mathrm{mg} / \mathrm{kg}$ DEX (high-dose group). The particular doses of DEX we used here followed the study of Roozendaal (Roozendaal, 2003). Saline and DEX were injected intraperitoneally $15 \mathrm{~min}$ prior to extinction training. After $24 \mathrm{~h}$, rats were tested for fear-potentiated startle in the absence of drugs. DEX facilitated extinction of conditioned fear in a dose-dependent manner (Figure 1b), eliciting a significant dose effect $\left(\mathrm{F}_{(3,28)}=3.31\right)$ showing a significant linear trend $\left(F_{(1,28)}=7.86\right)$. The low dose group showed a nonsignificant trend to facilitate extinction. Fear-potentiated startle was significantly lower in rats injected with 0.5 and $1.0 \mathrm{mg} / \mathrm{kg}$ DEX before extinction training $\left(\mathrm{t}_{(14)}=2.89, p<0.05\right.$, and $\mathrm{t}_{(14)}=3.02, p<0.05$, respectively) than in the control group. Since $1.0 \mathrm{mg} / \mathrm{kg}$ DEX produced the maximal enhancing effect, we used this dose in subsequent experiments (experiment 3,6,7, and 8). Previous studies have shown that lesions of the basolateral nucleus of the amygdala (BLA) block expression of fear-potentiated startle (Campeau and Davis, 1995). DEX may have a toxic effect on BLA, resulting in misinterpretation of its facilitation effects on extinction. To test for toxicity of DEX, all rats of experiment 1 were retrained and tested $24 \mathrm{~h}$ later. Rats previously injected with DEX or saline showed a significant fearpotentiated startle (Figure 1c). Thus, the facilitation effect of DEX observed during the postextinction test 1 appeared to result from an acute drug effect rather than from a more permanent, perhaps toxic, action of DEX. 


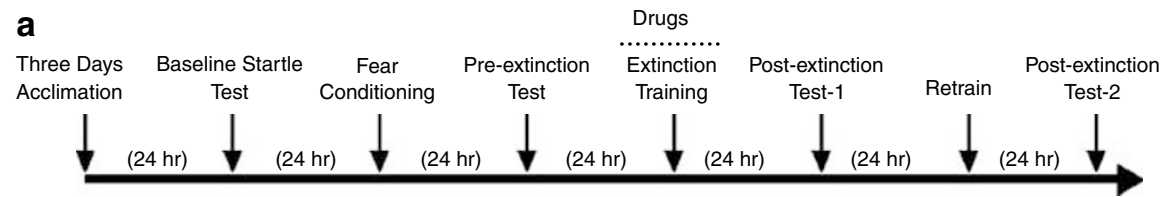

b

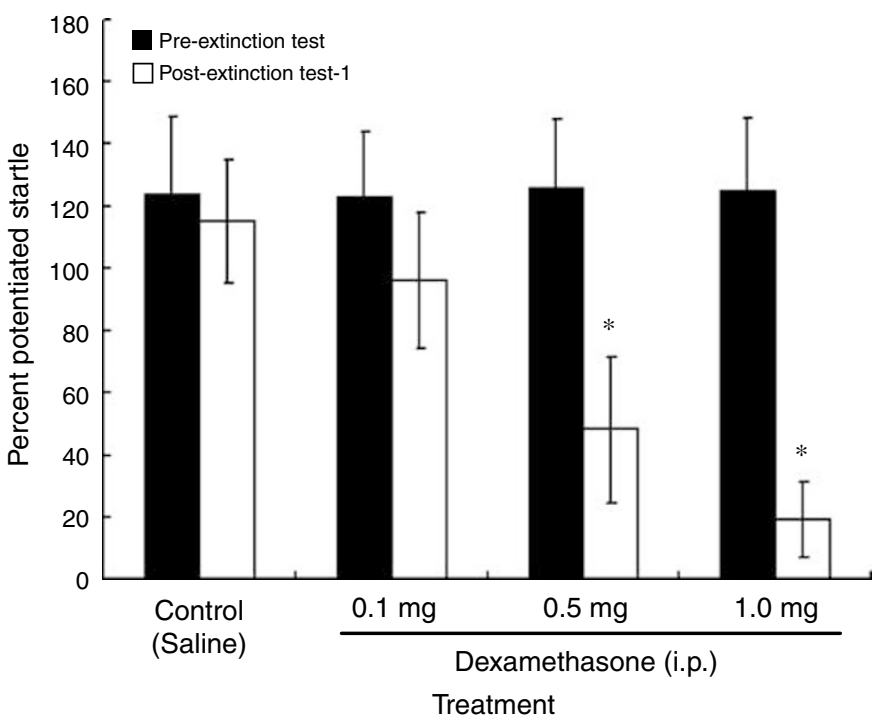

C

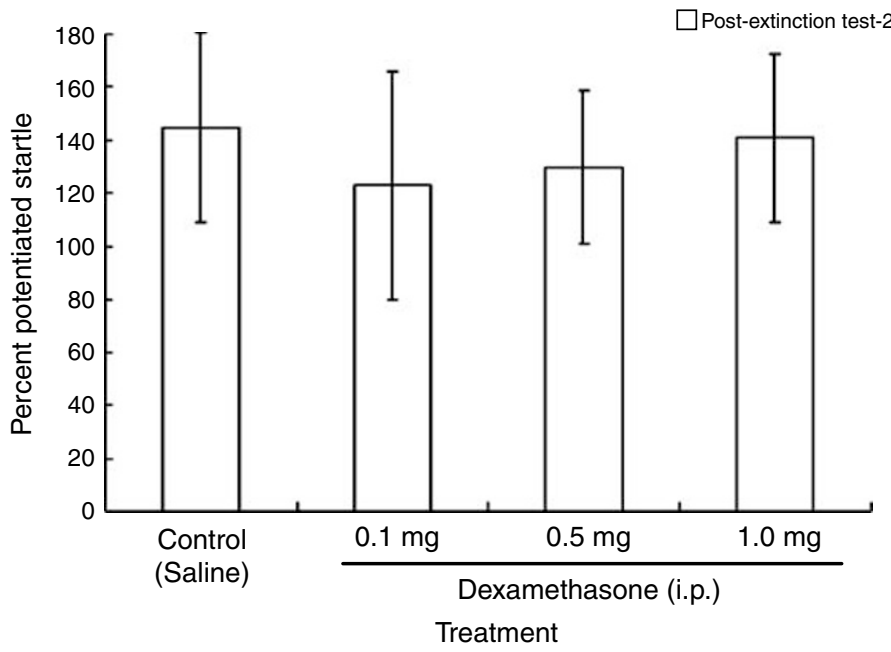

Figure I Systemic administration of glucocorticoid receptor agonist, DEX, facilitated extinction of conditioned fear in a dose-dependent manner. Timeline of the behavioral procedures for experiments I and 2 (a). Percent fear-potentiated startle measured $24 \mathrm{~h}$ before (pre-extinction test) and $24 \mathrm{~h}$ after extinction training (postextinction test-I)(b). Rats in each group underwent systemic administration of vehicle (saline) or DEX (0.I mg/ $\mathrm{kg}, 0.5 \mathrm{mg} / \mathrm{kg}$, or $1.0 \mathrm{mg} / \mathrm{kg}$, i.p.) $15 \mathrm{~min}$ prior to a single session of extinction training. After $24 \mathrm{~h}$, animals were tested for fear-potentiated startle in the absence of drugs. The same animals used in experiment I were retrained (c). After $24 \mathrm{~h}$ animals were tested for fear-potentiated startle in the absence of drugs (postextinction test-2). Values are mean $\pm \mathrm{SEM}, * *=0.05$ compared to the corresponding control.

\section{Experiment 2: Intra-Amygdala Administration of Glucocorticoid Receptor Agonist RU28362 Facilitated Extinction of Conditioned Fear}

In this experiment, we tested the possible effect of RU28362, a glucocorticoid receptor agonist, on the extinction of conditioned fear. Specifically, we were interested in whether intra-amygdala infusion of RU28362 would mimic the effect of systemic administered DEX. In all, 32 rats with intraamygdala cannulation received fear conditioning, extinction training, and testing for fear-potentiated startle. Initially, 40 were used, but eight were excluded. Rats were assigned into four groups of eight based on their level of fear-potentiated startle in the pre-extinction test. The groups received one of the following treatments: vehicle alone (control group) or different doses of glucocorticoid receptor agonist RU28362 $(0.5,1.0$, and $3.0 \mathrm{ng} /$ side, bilaterally). The doses of RU28362 we used here followed the study of Roozendaal (Roozendaal and McGaugh, 1997). Vehicle and RU28362 were infused into the BLA immediately before extinction training. After 
$24 \mathrm{~h}$, rats were tested for fear-potentiated startle in the absence of drugs. Intra-amygdala infusion of RU28362 enhanced extinction in a dose-dependent manner (Figure 2a), eliciting a significant dose effect $\left(\mathrm{F}_{(3,28)}=\right.$ 2.98) showing a significant linear trend $\left(\mathrm{F}_{(1,28)}=6.32\right)$. A low dose of RU28362 (0.5 ng/side) did not facilitate extinction. Medium and high dose of RU28362 (1.0 and $3.0 \mathrm{ng} /$ side) facilitated extinction significantly $\left(\mathrm{t}_{(14)}=2.94\right.$, $p<0.05$, and $t_{(14)}=3.43, p<0.05$, respectively) compared to the control group. To test for toxicity of RU28362, all rats were retrained and tested $24 \mathrm{~h}$ later. Animals previously injected with vehicle or RU28362 showed a strong fear-potentiated startle (Figure $2 \mathrm{~b}$ ), indicating the effects of RU28362 were not due to a nonspecific toxic effect. These results suggested that amygdaloid glucocorticoid receptors were involved in the extinction of conditioned fear.

\section{Experiment 3: Systemic Administration of the Corticosteroid Synthesis Inhibitor, Metyrapone, Blocked Extinction of Conditioned Fear}

Since experiment 1 showed that systemic administration of DEX facilitated the extinction of conditioned fear, we examined whether the corticosteroid synthesis inhibitor, metyrapone systematically injected would inhibit the extinction process. We also tested whether coadministration of DEX blocked the effect of metyrapone on extinction. A total of 48 rats received fear conditioning, extinction training, and testing for fear-potentiated startle. Initially, 57 rats were used, but nine were excluded. Rats were then assigned into six groups of eight based on their level of fearpotentiated startle in the pre-extinction test. Animals in groups 1-3 received vehicle + saline, metyrapone + saline, and metyrapone $+\mathrm{DEX}$, respectively. Metyrapone $(25 \mathrm{mg} / \mathrm{kg}$ s.c.) and DEX (1 mg/kg i.p.) were given 90 and $15 \mathrm{~min}$, respectively, prior to a single session of extinction training for a total of 2 days extinction training. The particular dose of metyrapone we used here followed the study of Roozendaal et al (1996) with some modification to reduce the possible nonspecific effect of high-dose metyrapone. At $24 \mathrm{~h}$ after the second extinction training, rats were tested for fear-potentiated startle in the absence of drugs. Groups 4-6 received the drug treatments described above, but were placed in the test chamber without extinction training (context exposure only). Results of an ANOVA indicated a significant treatment (control, metyrapone, and metyrapone $+\mathrm{DEX}$ ) by training (extinction training $v s$ context exposure) interaction $\left(\mathrm{F}_{(2,24)}=4.41\right)$. Administration of metyrapone significantly blocked extinction of conditioned fear $\left(\mathrm{t}_{(14)}=2.48 ; p<0.05\right)$. This effect was revealed by cotreatment with DEX (1.0 mg/kg i.p.). (Figure $3 \mathrm{~b})$. Fear-potentiated startle was significantly lower in rats treated with metyrapone and DEX before extinction training than in rats treated with metyrapone and saline before extinction training $\left(\mathrm{t}_{(14)}=2.86, p<0.05\right)$. The blockage effect of metyrapone and the unmasked effect of DEX required extinction training. Neither metyrapone nor DEX affected extinction in context exposure-treated groups (groups 4-6). The facilitation effect of DEX on the extinction was not the result of impaired expression of conditioned fear or accelerated forgetting.
Experiment 4: Systemic Administration of the Corticosteroid Synthesis Inhibitor, Metyrapone, Reduced Level of Circulating Corticosterone

We tested whether the dose of metyrapone used in this study blocked the level of circulating corticosterone level. Additional rats received fear conditioning, extinction training, and testing for fear-potentiated startle. Initially, 48 rats were used, but eight were excluded. Rats were then assigned into five groups of eight based on their level of fear-potentiated startle in the pre-extinction test. Metyrapone was given 90 min prior to a single session of extinction training for 1 or 2 days. Rats were decapitated immediately after the first or the second extinction training. Trunk blood was collected in heparinized $(500 \mathrm{U} / \mathrm{ml})$ tubes for immunoassay for corticosterone. Compared with control group (Figure 4b, lane one), the circulating corticosterone level increased after the second extinction training (Figure $4 \mathrm{~b}$, lane four). Administration of the corticosteroid synthesis inhibitor metyrapone $(25 \mathrm{mg} / \mathrm{kg})$, blocked the enhanced effect of extinction training on the level of circulating corticosterone $\left(\mathrm{t}_{(14)}=3.82, p<0.05\right)$ (Figure $4 \mathrm{a}$, lane five). The inhibitory effect of metyrapone on the extinction of fear conditioning may be mediated by blocking synthesis of glucocorticoid.

\section{Experiment 5: Effects of Intra-Amygdala Infusion of the Glucocorticoid Receptor Antagonist, Mifepristone, on Extinction}

To provide further evidence that activation of amygdaloid glucocorticoid receptors modulates extinction of conditioned fear, we examined whether infusion of the glucocorticoid receptor antagonist, mifepristone (RU38486), into the BLA would inhibit the extinction process. Previous results showed that RU38486 is an appropriate tool for studying the function of glucocorticoid on fear conditioning (Pugh et al, 1997a, b; Cordero et al, 1998). In all, 32 rats with intra-amygdala cannulation received fear conditioning, extinction training, and testing for fear-potentiated startle. Initially, 41 rats were used, but nine were excluded. Rats were then assigned into four groups of eight animals based on their level of fear-potentiated startle in the pre-extinction test. Groups received one of the following treatments: vehicle (control group), $1 \mathrm{ng} /$ side RU38486 (low-dose group), $2 \mathrm{ng} /$ side RU38486 (medium dose group) or $5 \mathrm{ng} /$ side RU38486 (high-dose group). The doses of RU38486 we used here followed the study of Rooendaal (Roozendaal and McGaugh, 1997). Vehicle and RU38486 were administered $10 \mathrm{~min}$ prior to a single session of extinction training for a total of 2 days. At $24 \mathrm{~h}$ after the second extinction training, animals were tested for fear-potentiated startle in the absence of drugs. Intra-amygdala administration of RU38486 blocked extinction of conditioned fear in a dose-dependent manner (Figure 5b) elicited a significant dose effect $\left(\mathrm{F}_{(3,28)}=3.72\right)$ with a significant linear trend $\left(\mathrm{F}_{(1,28)}=7.69\right)$. The low-dose group did not show any effect on the extinction. The medium-dose group showed a trend to block extinction, but did not reach a significant level. Fear-potentiated startle was significantly lower in the highdose group $\left(t_{(14)}=2.74\right)$ than in the control. These results supported our assumption that activation of amygdaloid 

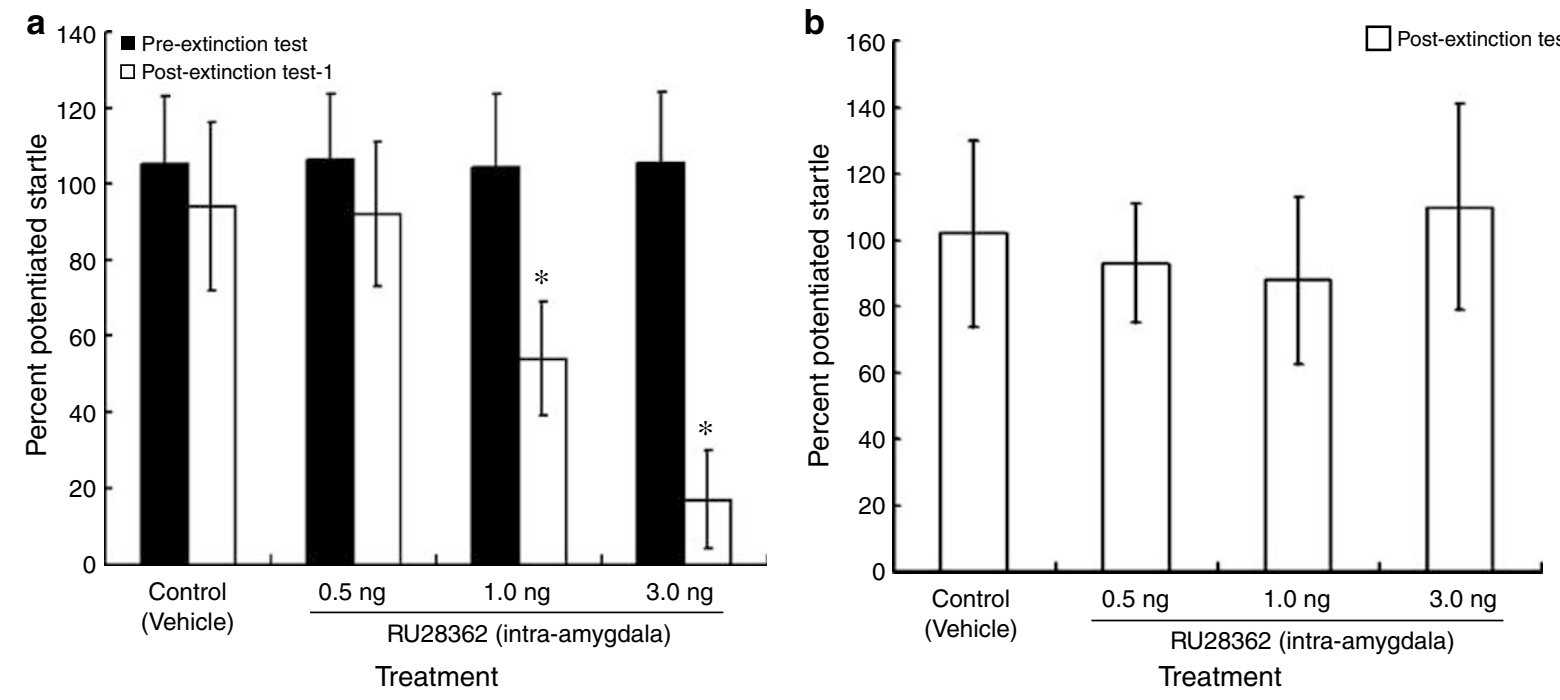

C

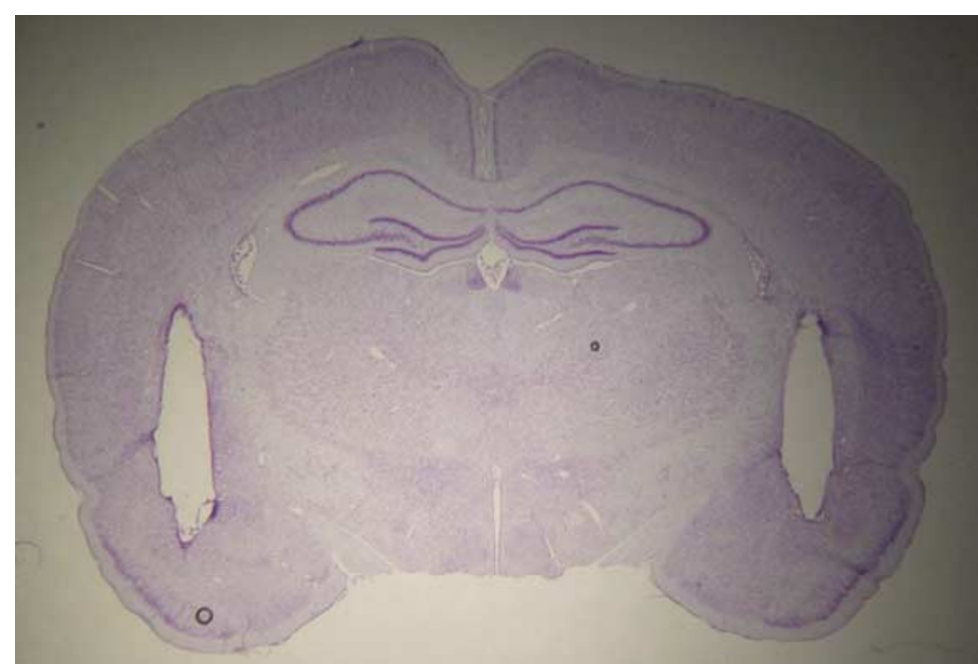

d

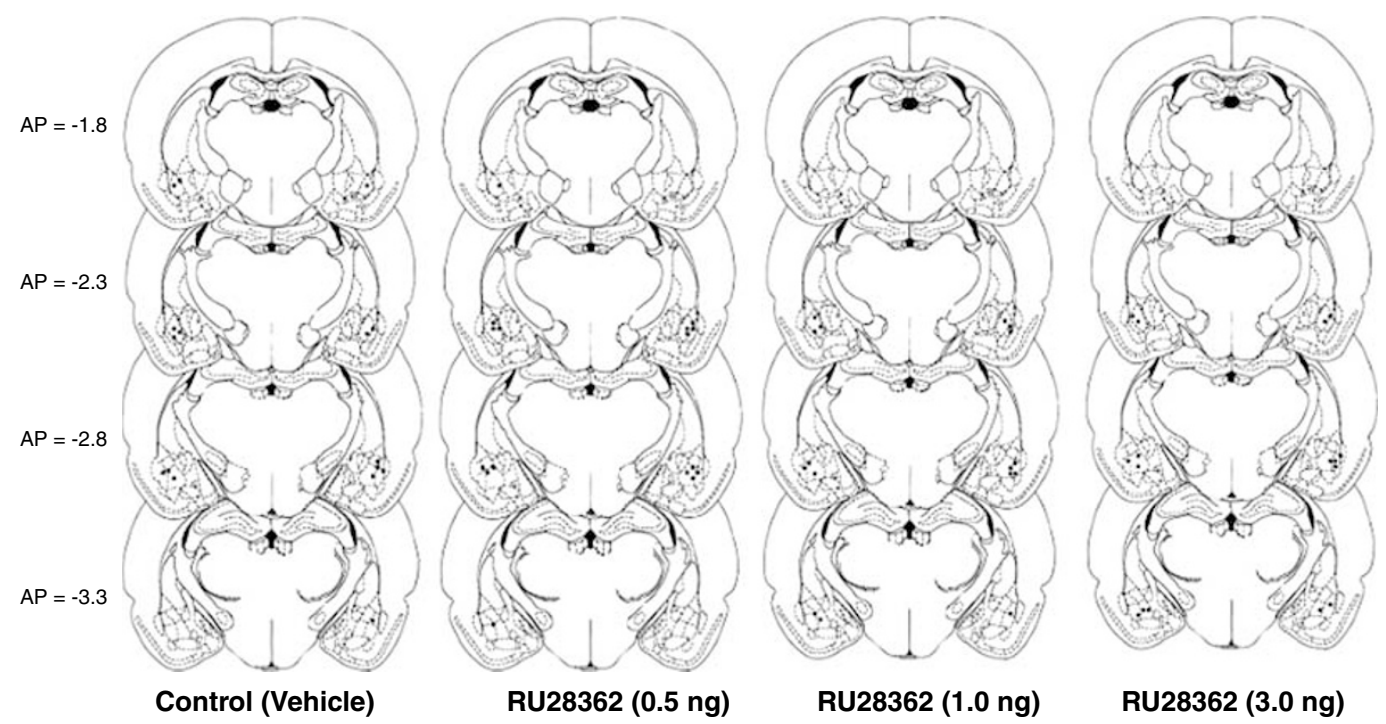

Figure 2 Intra-amygdala infusion of glucocorticoid receptor agonist, RU28362, facilitated extinction of conditioned fear in a dose-dependent manner. Percent fear-potentiated startle measured $24 \mathrm{~h}$ before (pre-extinction test) and $24 \mathrm{~h}$ after extinction training (postextinction test- $\mathrm{I}$ ) (a). Rats in each group underwent intra-amygdaloid infusion of vehicle (20\% DMSO) or RU28362 (0.5, 1.0, or $3.0 \mathrm{ng} /$ side, bilaterally) I 5 min prior to a single session of extinction training. After $24 \mathrm{~h}$, animals were tested for fear-potentiated startle in the absence of drug. The same animals used in experiment 2 were retrained (b). After $24 \mathrm{~h}$ animals were tested for fear-potentiated startle in the absence of drug (postextinction test-2). Values are mean \pm SEM, * $=p<0.05$ compared to the corresponding control. Representative figure for the tip placement (c). Cannula tip placements transcribed onto atlas plates adapted from Paxinos and Watson (1997) (d). 


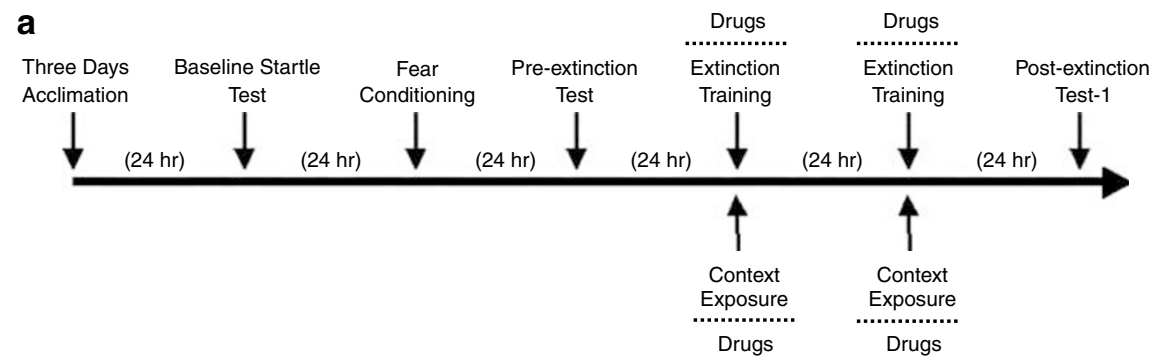

b

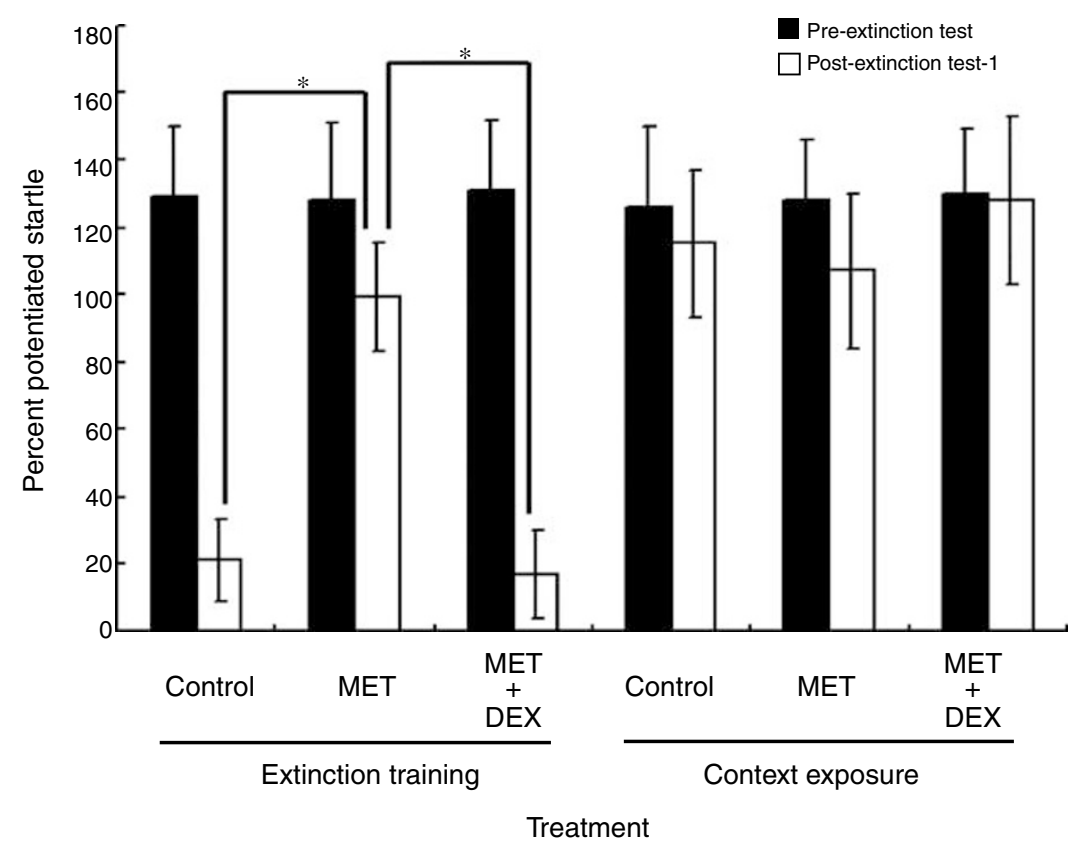

Figure 3 Administration of corticosteroid synthesis inhibitor, metyrapone, blocked extinction of conditioned fear. This effect was exposed by cotreatment with synthetic glucocorticoid receptor agonist DEX. Timeline of the behavioral procedures for experiment 3 (a). Percent fear-potentiated startle measured $24 \mathrm{~h}$ before (pre-extinction test) and $24 \mathrm{~h}$ after extinction training or context exposure (postextinction test- $\mathrm{I}$ ) (b). Rats in each group underwent systemic administration of vehicle (control), metyrapone alone (MET) or MET + DEX 15 min prior to a single session of extinction training (with CS) or context exposure (without CS). After $24 \mathrm{~h}$, animals were tested for fear-potentiated startle in the absence of drugs. Values are mean \pm SEM, * $=p<0.05$ comparing to the control group.

glucocorticoid receptors modulated extinction of conditioned fear.

\section{Experiment 6: Effects of Coadministration of DEX and the Glucocorticoid Receptor Antagonist, Mifepristone, on Extinction}

To clarify the role of amygdaloid glucocorticoid receptors in the DEX enhancement effect on the extinction of conditioned fear, 40 rats with intra-amygdala cannulation received fear conditioning, extinction training, and testing for fear-potentiated startle. Rats were then randomly assigned to five groups of eight. Initially, 48 rats were used, but eight were excluded. Groups 1-5 received vehicle + saline, vehicle + DEX (1 mg/kg), RU38486 (1 ng/side) + DEX $(1 \mathrm{mg} / \mathrm{kg}), \quad$ RU38486 (2 ng/side) + DEX (1 mg/kg), and RU38486 (5 ng/side) + DEX (1 mg/kg), respectively (Figure 4a). RU38486 was given $10 \mathrm{~min}$ prior to DEX injection. At $15 \mathrm{~min}$ after DEX injection, rats received a single session of extinction training. After $24 \mathrm{~h}$, rats were tested for fear-potentiated startle in the absence of drugs.
Infusion of RU38486 into the BLA blocked the DEX enhancement effect on extinction, eliciting a significant dose effect $\left(\mathrm{F}_{(3,28)}=3.68\right)$. Infusion of 2 or $5 \mathrm{ng} \mathrm{RU} 38486$ completely blocked DEX effect $\left(\mathrm{t}_{(14)}=2.86, p<0.05\right.$, and $\mathrm{t}_{(14)}=3.89, p<0.05$, respectively) (Figure $6 \mathrm{~b}$ ). In Figure $5 \mathrm{~b}$, we showed that infusion of $2 \mathrm{ng}$ RU38486 into the BLA did not affect extinction. Here, we demonstrated that a dose of $2 \mathrm{ng} /$ side of RU38486 blocked the facilitating effect of DEX. Therefore, the facilitation effect of DEX on extinction was mediated by the amygdaloid glucocorticoid receptors. The facilitation effect of DEX on extinction should be blocked by intra-amygdala infusion of RU38486. Activation of the glucocorticoid receptors modulated the extinction of conditioned fear.

\section{Experiment 7: Systemic Administration of DEX after Extinction Training Facilitated Extinction of Conditioned Fear}

Recent studies show that systemic or intra-amygdala infusion of drugs after extinction training facilitate or 


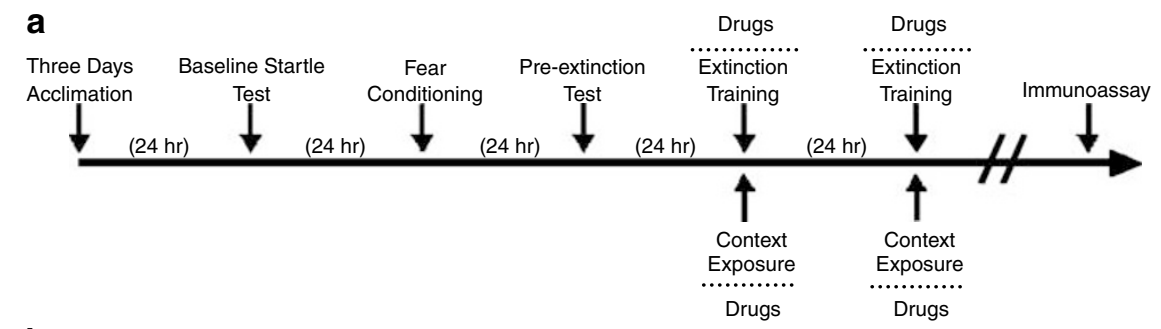

b

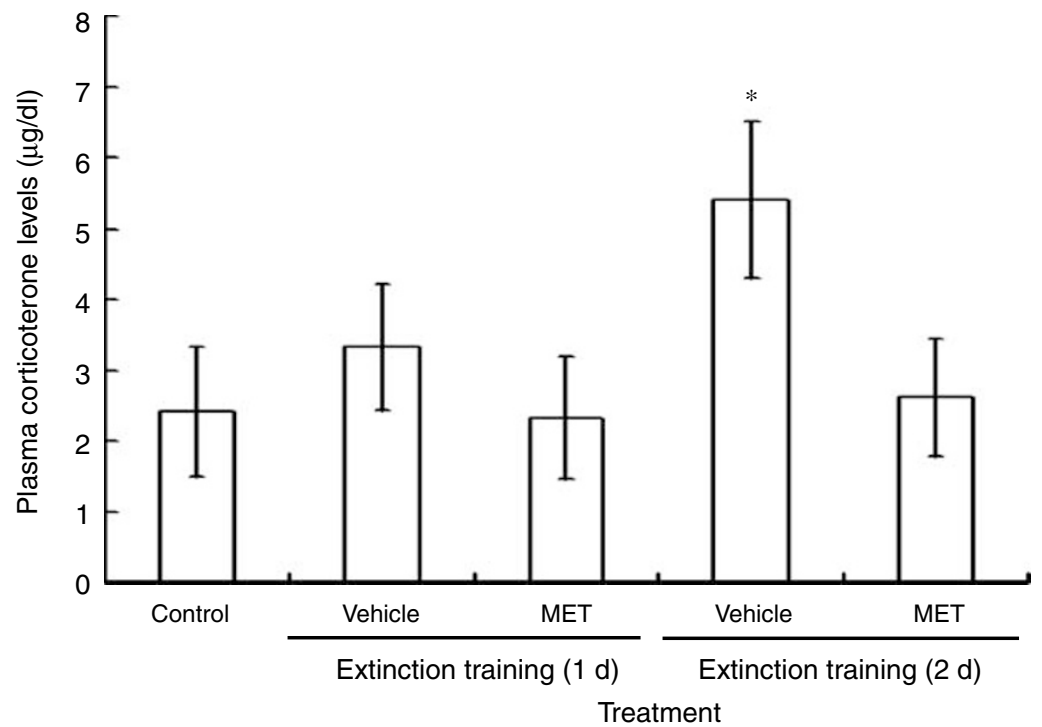

Figure 4 Systemic administration of the corticosteroid synthesis inhibitor, metyrapone, reduced circulating corticosterone level. Timeline of the behavioral procedures for experiment 4 (a). Metyrapone was given 90 min prior to a single session of extinction training (b). Animals were killed after the first or the second extinction training and plasma corticosterone levels (mean \pm SEM) in $\mathrm{mg} / \mathrm{dl}$ were assessed immediately.

impair extinction (Roozendaal, 2003; Richardson et al, 2004), suggesting that the amygdala is involved in the postlearning consolidation phase of the extinction memory. We predicted that postextinction training, administration of DEX also facilitates the extinction of conditioned fear. To test this hypothesis, 16 rats received fear conditioning, extinction training, and testing for fear-potentiated startle. Initially, 19 rats were used, but three were excluded. Rats were then randomly assigned to two different groups and received saline $(\mathrm{SAL})$ or DEX $(1 \mathrm{mg} / \mathrm{kg})$. Results showed that systemic administration of DEX after extinction training facilitated extinction of conditioned fear $\left(\mathrm{t}_{(14)}=\right.$ $3.62, p<0.05$,) (Figure 7b). The DEX facilitation effect on extinction may influence the memory consolidation phase of extinction.

\section{Experiment 8: Effect of Pretest DEX and Metyrapone Administration on Fear-Potentiated Startle}

Administration of a low dose of glucocorticoid can increase startle reflexes in humans (Buchanan et al, 2001). Larger doses can decrease startle reflexes to emotional stimuli (Buchanan and Lovallo, 2001). We tested whether the effect of the drugs used in this study were secondary to effect on fear itself or to CS processing. For example, if DEX enhanced CS-elicited fear, this might facilitate extinction by increasing the discrepancy between what the CS predicted and what actually occurred. If metyrapone interfered with visual processing, it might block the extinction produced by nonreinforced exposures to the visual CS. To evaluate these possibilities, 18 rats received acclimation, baseline startle test, and fear conditioning. Initially, 22 rats were used, but four of them were excluded. After $24 \mathrm{~h}$, rats were infused with DEX or metyrapone. At $15 \mathrm{~min}$ (DEX) or $90 \mathrm{~min}$ (metyrapone) after infusion, rats were tested for fear-potentiated startle. As shown in Figure 8, the dose of DEX or metyrapone used here did not significantly influence fear-potentiated startle when administrated before testing $\left(\mathrm{F}_{(1,14)}=0.873\right)$. Thus, it is unlikely that these drugs influenced extinction by increasing fear or disrupting CS processing.

\section{DISCUSSION}

We found that systemic administration and intra-amygdala infusion of glucocorticoid receptor agonists (DEX and RU28362) facilitated the extinction of conditioned fear (experiments 1 and 2). This facilitation effect was dependent on repeated presentation of the conditioned stimulus rather than simple exposure to the experimental context, indicating that it was not the result of impaired expression of conditioned fear or accelerated forgetting (experiment 3 ). DEX- or RU28362-facilitated extinction of conditioned fear could be reinstated by retraining (experiments 1 and 2). Extinction of conditioned fear was blocked by 

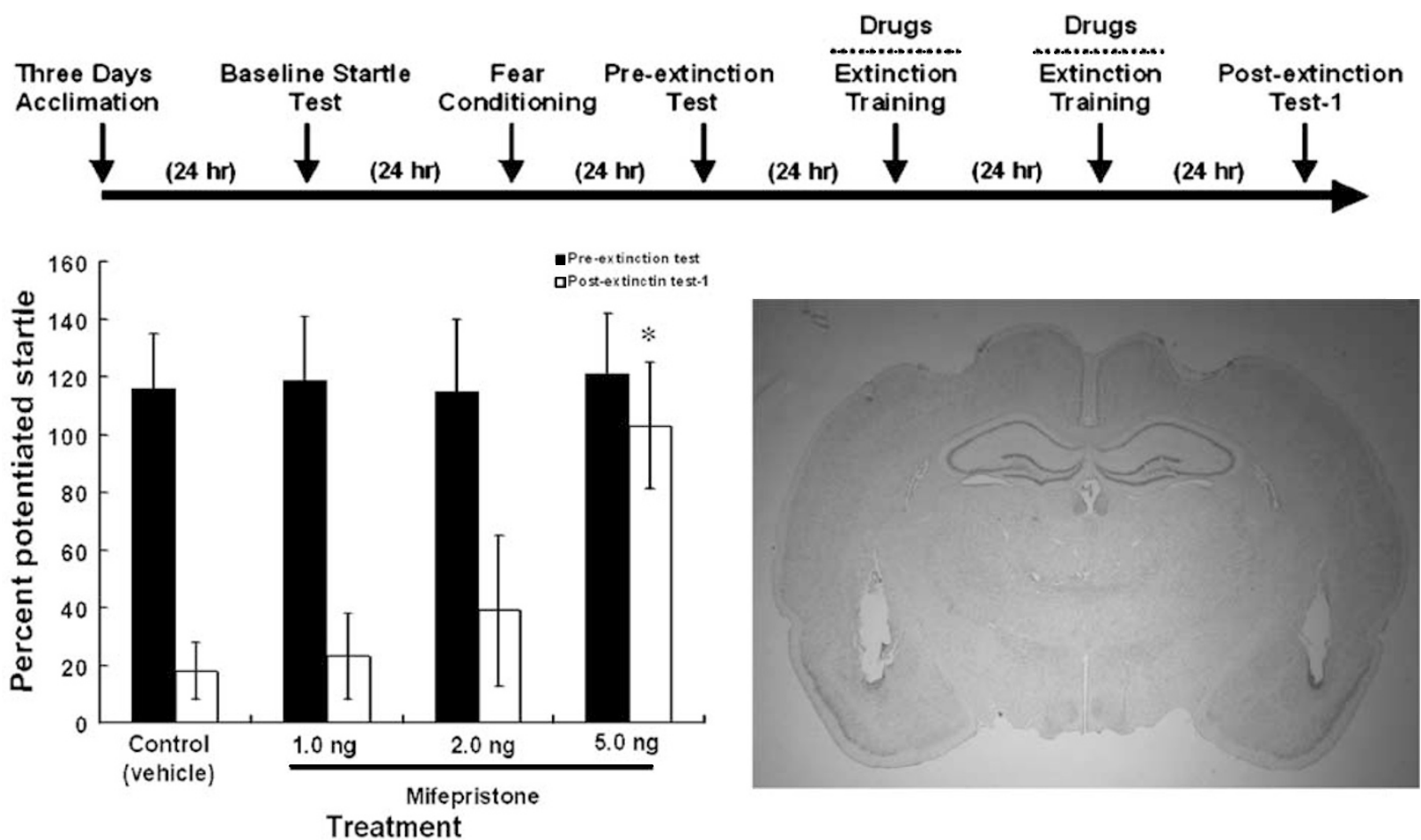

Treatment

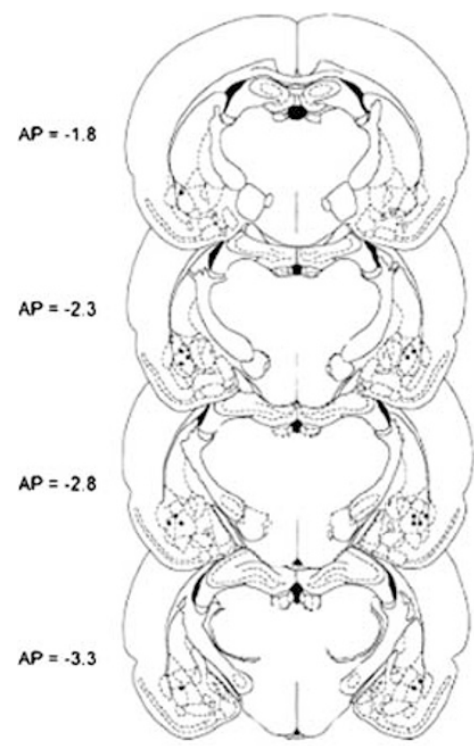

Control (vehicle)

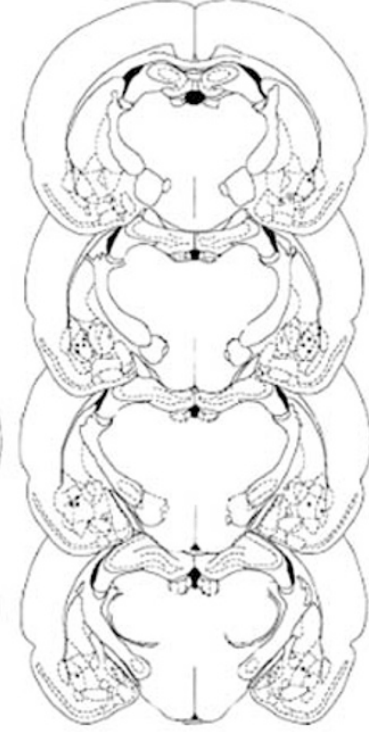

$1.0 \mathrm{ng}$ Mifepristone

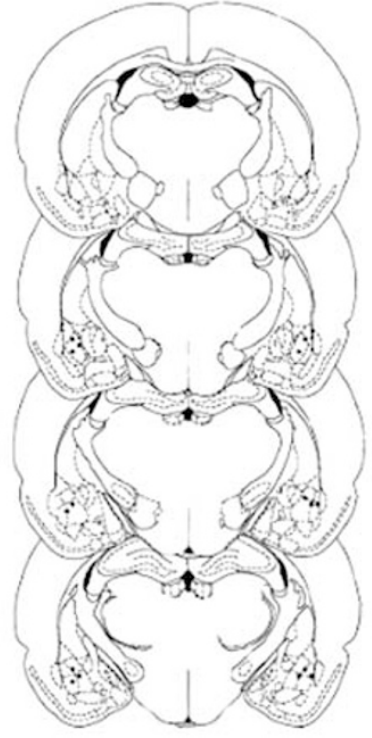

$2.0 \mathrm{ng}$ Mifepristone

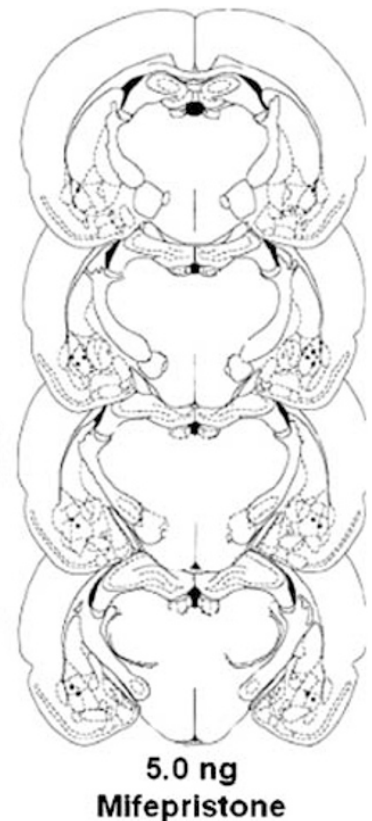

Figure 5 Intra-amygdala infusion of glucocorticoid receptor antagonist, mifepristone, blocked extinction of conditioned fear in a dose-dependent manner Timeline of the behavioral procedures for experiment 5 (a). Percent fear-potentiated startle measured $24 \mathrm{~h}$ before (pre-extinction test) and $24 \mathrm{~h}$ after extinction training (postextinction test- I) (b). Rats in each group underwent intra-amygdala infusion of vehicle (control group) or mifepristone (I.0, 2.0, or $5.0 \mathrm{ng} / \mathrm{side}$, bilaterally) $10 \mathrm{~min}$ prior to a single session of extinction training for a total of 2 days. After $24 \mathrm{~h}$, animals were tested for fear-potentiated startle in the absence of drugs. Values are mean \pm SEM, $*=p<0.05$ compared to the control. Representative figure for the tip placement (c). Cannula tip placements transcribed onto atlas plates adapted from Paxinos and Watson (1997) (d).

administration of corticosteroid synthesis inhibitor metyrapone $(25 \mathrm{mg} / \mathrm{kg}$ s.c.) $90 \mathrm{~min}$ before extinction training. The blockage effect of metyrapone was removed by systemic injection of DEX. These results suggest that endogenous glucocorticoid is required for extinction. Furthermore, the DEX enhancement effect was prevented by intra-amygdala infusion of glucocorticoid receptor antagonist, RU38486, at the doses that did not affect extinction (experiment 5). In addition, the dose of glucocorticoid agonists used in this study did not alter baseline startle levels (experiment 8 ). The facilitation effect of DEX and RU28362 could not be attributed to nonspecific effects of glucocorticoid on startle 

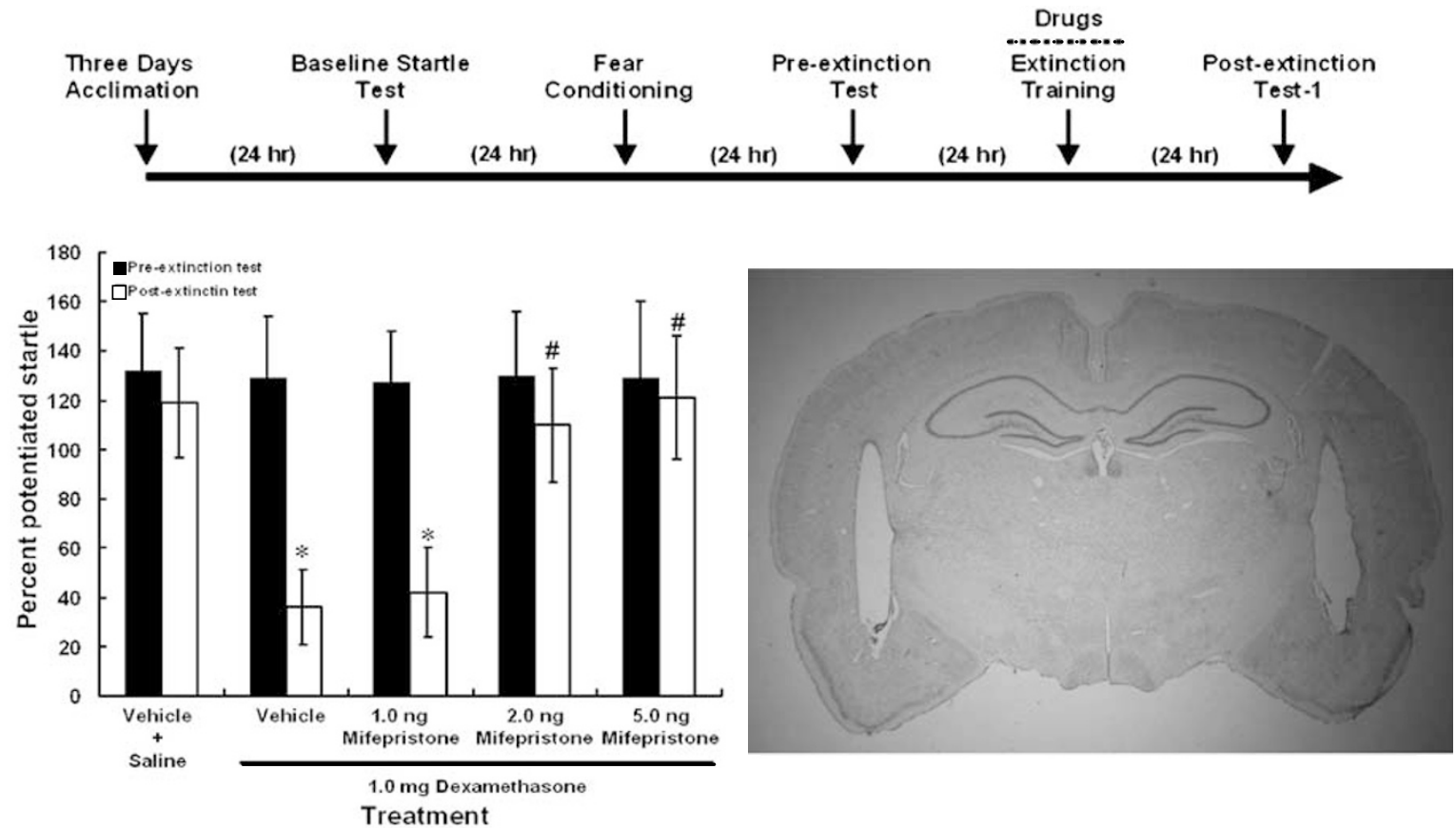

Treatment
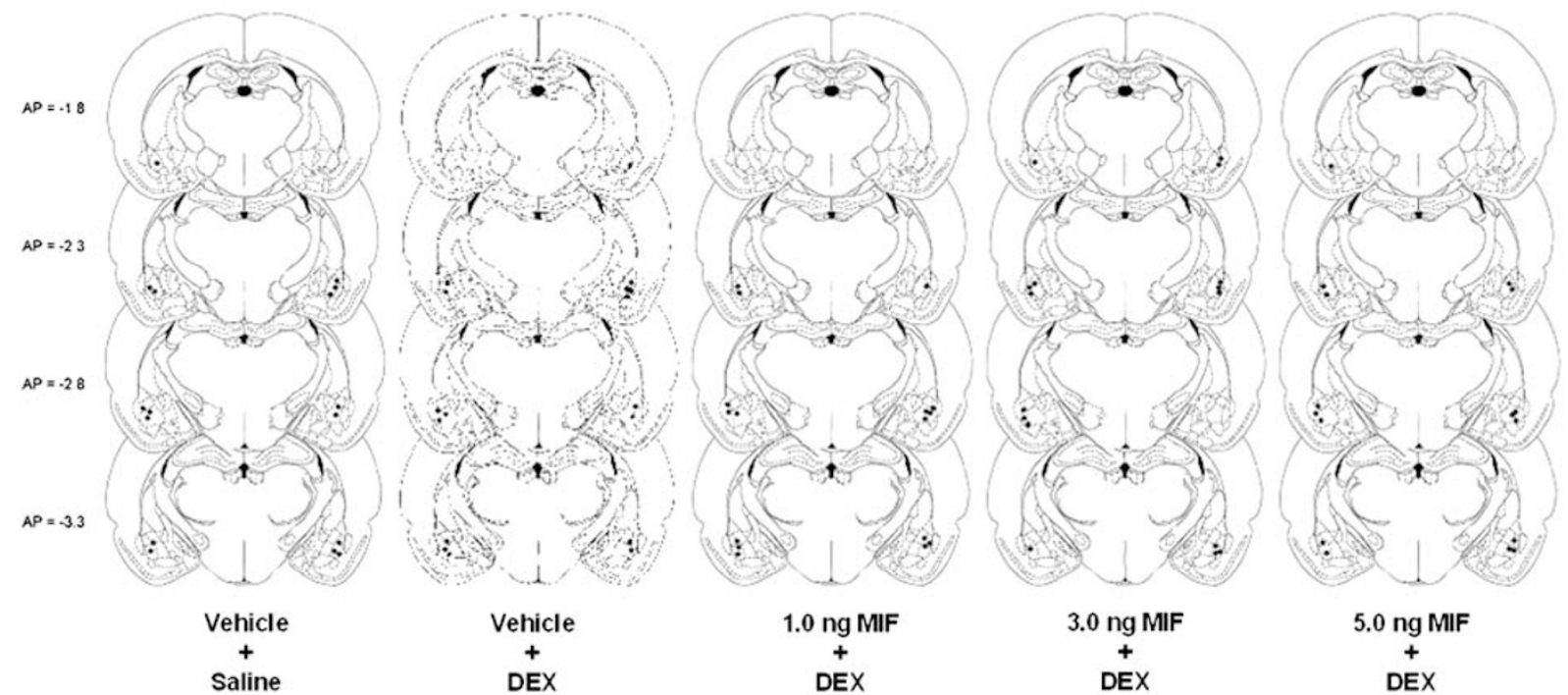

Figure 6 The facilitation effect of DEX was blocked by intra-amygdala infusion of glucocorticoid receptor antagonist, mifepristone (MIF). Timeline of the behavioral procedures for experiment 6 (a). Percent fear-potentiated startle measured $24 \mathrm{~h}$ before (pre-extinction test) and $24 \mathrm{~h}$ after extinction training (postextinction test-I) (b). Rats in each group underwent intra-amygdala infusion of vehicle (control), mifepristone (MIF, I.0, 2.0, or 5.0 ng/side, bilaterally) 10 min prior to saline or DEX injection. At 15 min after the injection, animals received a single session of extinction training. After $24 \mathrm{~h}$, animals were tested for fear-potentiated startle in the absence of drugs. Values are mean \pm SEM, $*=p<0.05$ compared to the vehicle + saline group; $\#=p<0.05$ comparing to the vehicle + DEX group. Representative figure for the tip placement (c). Cannula tip placements transcribed onto atlas plates adapted from Paxinos and Watson (1997) (d).

response. Therefore, activation of the amygdaloid glucocorticoid receptors modulated the extinction of conditioned fear.

Corticosteroids participate in the extinction of conditioned fear. The amygdala and hippocampus, specific to the extinction of conditioned fear, contain glucocorticoid receptors (Fuxe et al, 1985; Van Eekelen et al, 1987; Korte, 2001). A recent study showed that administration of metyrapone impaired the extinction of conditioned freezing (Barrett and Gonzalez-Lima, 2004). We found that RU28362 infusion to the BLA facilitated extinction and intraamygdala administration of RU38486 blocked the DEX facilitation effect on extinction. These results suggest that the BLA is a critical locus for the glucocorticoid enhancement of fear extinction. Numerous studies have suggested that other brain regions including the hippocampus and medial prefrontal cortex (mPFC) are also important for the extinction (Quirk et al, 2000; Herry and Garcia, 2002; Vianna et al, 2001). Further experiments such as local infusion of glucocorticoid agonist and antagonist 


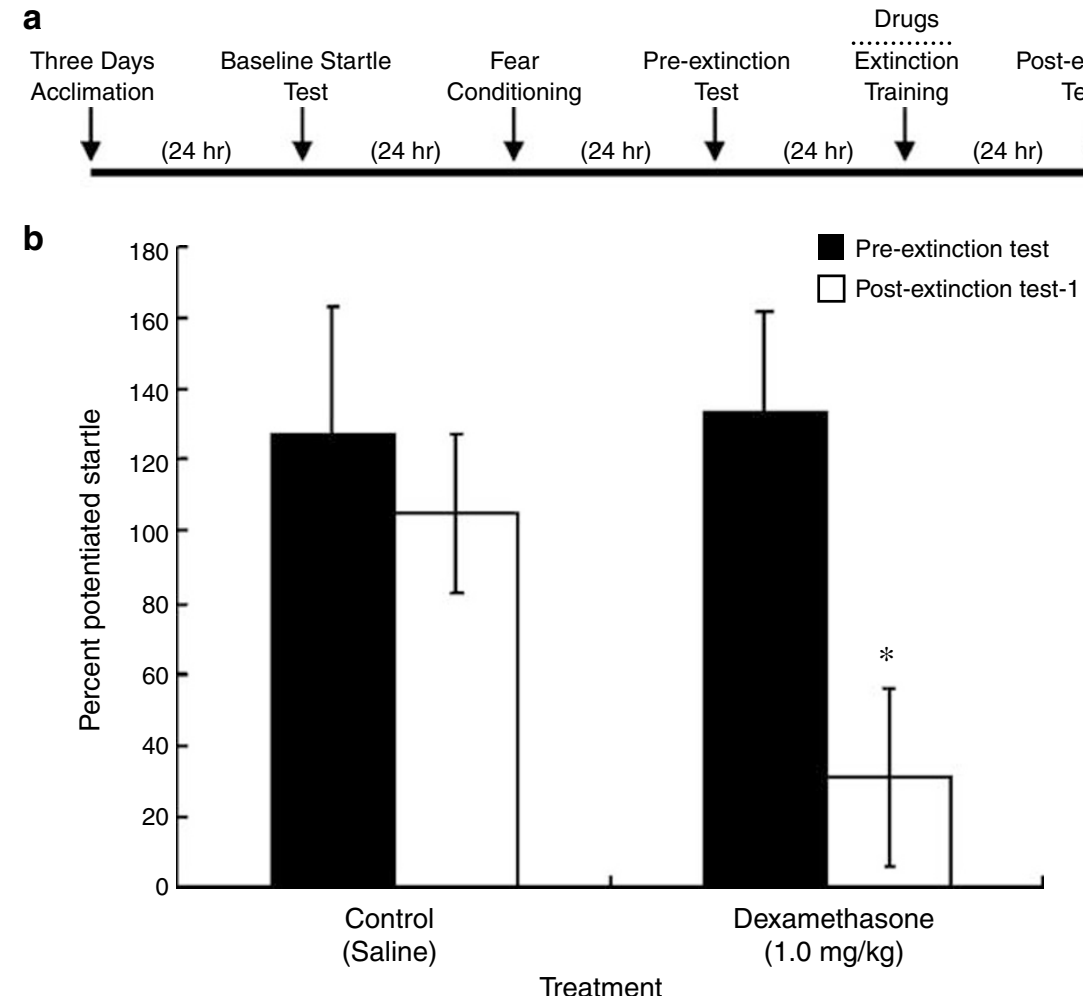

Figure 7 Systemic administration of DEX after extinction training facilitated extinction of conditioned fear. Timeline of the behavioral procedures for experiment 7 (a). Percent fear-potentiated startle measured $24 \mathrm{~h}$ before (pre-extinction test) and $24 \mathrm{~h}$ after extinction training (postextinction test- $\mathrm{I}$ ) (b). Rats in each group underwent systemic injection of saline or DEX $(\mathrm{I} \mathrm{mg} / \mathrm{kg})$ immediately after a single session of extinction training. After $24 \mathrm{~h}$, animals were tested for fear-potentiated startle in the absence of drugs. Values are mean $\pm \mathrm{SEM}$, $*=p<0.05$ compared to the saline control.

\section{a}
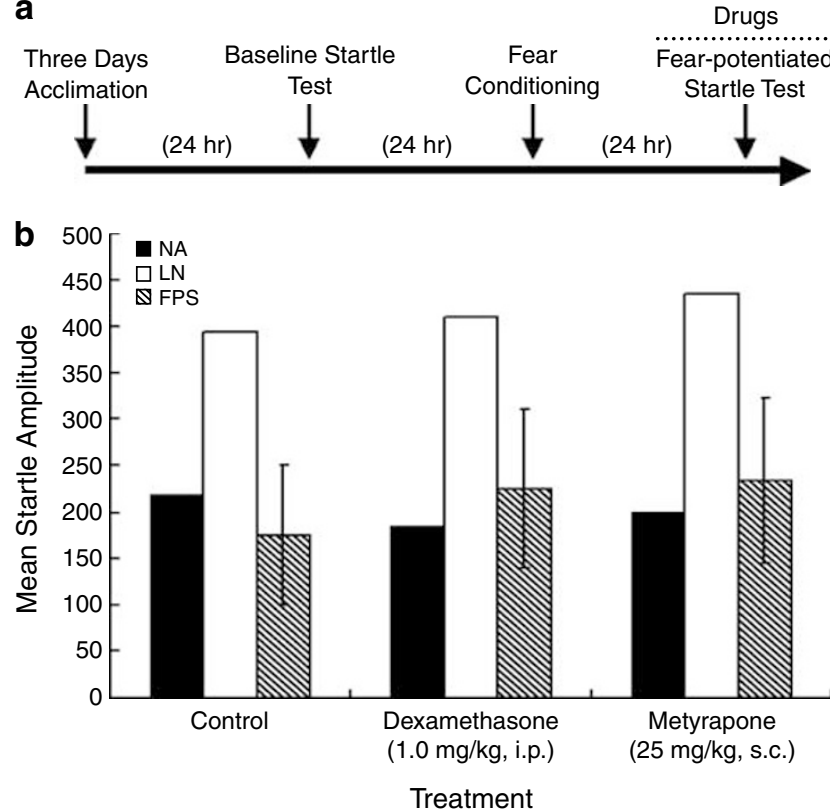

Figure 8 Effect of pretest DEX and metyrapone administration on fear-potentiated startle. Timeline of the behavioral procedures for experiment 8 (a). Metyrapone $(25 \mathrm{mg} / \mathrm{kg})$ and DEX $(\mathrm{Img} / \mathrm{kg})$ were injected intraperitoneally 90 and 15 min, respectively, prior to the fearpotentiated startle test. Values are mean \pm SEM, $*=p<0.05$ compared to the control (NA= noise alone, $L N=$ light-noise, $F P S=$ fear-potentiated startle). into the $\mathrm{mPFC}$ and hippocampus are required to identify the role of $\mathrm{mPFC}$ and hippocampus in the facilitation effect of DEX.

Roozendaal and McGaugh (1997) recently indicated that glucocorticoids may act directly in the amygdala to influence memory consolidation. To test the effect of glucocorticoid on the consolidation of extinction, we administered DEX immediately after extinction training (experiment 7). We found that DEX facilitated extinction of conditioned fear. This means that glucocorticoid may facilitate extinction by enhancing consolidation of extinction memory. Sotres-Bayon et al (2004) showed that extensive damage to the BLA did not interfere with the extinction of tone-elicited fear response. They suggest that BLA is not essential for the extinction of fear conditioning. Roozendaal and McGaugh's findings, however, indicate that lesions of the amygdala do not necessarily result in memory impairment but block stress hormone effects on memory consolidation. This is because the amygdala interacts with other brain regions, including the hippocampus and $\mathrm{mPFC}$, to regulate stress hormone effects on memory (Roozendaal et al, 2002; Roozendaal, 2003). Our findings match previous findings by indicating that glucocorticoids acted in the amygdala to influence extinction, but BLA lesions alone did not block extinction of conditioned fear.

Glucocorticoid levels are generally elevated during fear or anxiety (Lyons et al, 1999). Corticotropin-releasing 
hormone (CRH) is involved in the glucocorticoid behavioral responses to fear stimuli. Elevated cortisol concentrations in the brain promote $\mathrm{CRH}$ gene expression in the central nucleus of the amygdala (CeA). They also promote $\mathrm{CRH}$ expression in the bed nucleus of the stria terminalis, which can also increase cortisol and CRH concentration in the CeA. Consequently, it can increase norepinephrine activity in the locus coeruleus. This enhances the perception of fear and anxiety-inducing stimuli, ultimately increasing fearrelated behavior (Erickson et al, 2003). In the present study, we administered DEX intraperitoneally and RU28362 via intra-amygdala infusion into BLA. Therefore, we cannot exclude the possible role of $\mathrm{CeA}$ in the facilitating effect of glucocorticoid on extinction. Further experiments are needed to clarify the role of $\mathrm{CeA}$ on the facilitation effect of DEX on extinction. DEX poorly penetrates into the brain (De Kloet et al, 1975) because of the activity of multiple drug resistance gene $\mathrm{A}$ in the blood-brain barrier (Meijer et al, 1998). Therefore, DEX poorly substitutes for depletion of the endogenous glucocorticoid from the brain and may cause a condition resembling that of adrenalectomy. The possible risk of using DEX in the treatment of PTSD patients must be noted.

Progressive extinction of fear memory is important for psychiatric disorders such as PTSD. Our finding was consistent with recent clinical studies showing that PTSD patients often have reduced cortisol level, which may explain their inability to shown normal fear extinction (Yehuda et al, 2004). Aerni et al (2004) found that daily administration of cortisol reduced symptoms of traumatic memory in PTSD patients. Schelling et al (2004) showed that prolonged high-dose glucocorticoid treatment after trauma reduces the risk of humans developing PTSD. The mechanisms of these treatments may involve glucocorticoid effects on the retrieval and extinction of traumatic memories.

\section{Conclusions}

We showed that activation of the amygdaloid glucocorticoid receptors facilitated the extinction of fear conditioning as measured by fear-potentiated startle. Systemic injection of corticosteroid synthesis inhibitor (metrypone) blocked extinction. Systemic or intra-amygdaloid administration of glucocorticoid receptor agonists enhanced the extinction of conditioned fear memories when given immediately after or prior to extinction learning. This enhancement was blocked by cotreatment with glucocorticoid receptor antagonist (RU38486). Increased understanding of the mechanisms involved in the extinction process may be very useful in treatment of psychiatric disorders involving dysregulated fear responses.

\section{ACKNOWLEDGEMENTS}

We thank Dr YM Weng for his critical reading and suggestions on the manuscript. This work was supported by grants from the National Science Council, Taiwan (NSC93-2320-B-003-003; NSC92-2614-B-003-001; NSC902320-B-003-007). Our gratitude also goes to the Academic Paper Editing Clinic, National Taiwan Normal University.

\section{REFERENCES}

Aerni A, Traber R, Hock C, Roozendaal B, Schelling G, Papassotiropoulos A et al (2004). Low-dose cortisol for symptoms of posttraumatic stress disorder. Am J Psychiatr 161: 1488-1490.

Baez M, Volosin M (1994). Corticosterone influences forced swiminduced immobility. Pharmacol Biochem Behav 49: 729-736.

Barrett D, Gonzalez-Lima F (2004). Behavioral effects of metyrapone on Pavlovian extinction. Neurosci Lett 371: 91-96.

Barrett D, Shumake J, Jones D, Gonzalez-Lima F (2003). Metabolic mapping of mouse brain activity after extinction of a conditioned emotional response. J Neurosci 23: 5740-5749.

Bitran D, Shiekh M, Dowd JA, Dugan MM, Renda P (1998). Corticostreone is permissive to the anxiolytic effects that results from the blockade of hippocampal mineralocorticoid receptors. Pharmacol Biochem Behav 60: 879-887.

Bohus B, De Kloet RE, Veldhuis HD (1982). Adrenal Steroids and Behavioral Adaptation: Relationship to Brain Corticoid Receptors. Adrenal Actions on Brain. Springer-Verlag: Berlin. pp 107-148.

Bouton ME (2002). Context, ambiguity, and unlearning: Sources of relapse after behavioral extinction. Biol Psychiatr 52: 976-986.

Buchanan TW, Brechtel A, Sollers JJ, Lovallo WR (2001). Exogenous cortisol exerts effects on the startle reflex independent of emotional modulation. Pharmacol Biochem Behav 68: 203-210.

Buchanan TW, Lovallo WR (2001). Enhanced memory for emotinal material following stress-level cortisol treatment in humans. Psychoneuroendocrinology 26: 307-317.

Campeau S, Davis M (1995). Involvement of the central nucleus and basolateral complex of the amygdala in fear conditioning measured with fear-potentiated startle in rats trained concurrently with auditory and visual conditioned stimuli. J Neurosci 15: 2301-2311.

Cassella J, Davis M (1986). The design and calibration of a startle measurement system. Physiol Behav 36: 377-383.

Cordero MI, Kruyt ND, Merino JJ, Sandi C (2002). Glucocorticoid involvement in memory formation in a rat model for traumatic memory. Stress 5: 73-79.

Cordero MI, Merino JJ, Sandi C (1998). Correlational relationship between shock intensity and corticosterone secretion on the establishment and subsequent expression of contextural fear conditioning. Behav Neurosci 112: 885-891.

Cordero MI, Sandi C (1998). A role for brain glucocorticoid receptors in contextual fear conditioning: dependence upon training intensity. Brain Res 786: 11-17.

Dadds M, Bovbjerg D, Redd W, Cutmore T (1997). Imagery in human classical conditioning. Psychol Bull 122: 89-103.

Davis M (2000). The role of the amygdala in conditioned and unconditioned fear and anxiety. In: Aggleton JP (ed). The Amygdala. Oxford University Press: Oxford, UK. pp 213-287.

Davis M, Falls WA, Gewirtz J (2000). Neural systems involved in fear inhibition: Extinction and conditioned inhibition. In: Myslobodsky M, Weiner I (eds). Contemporary Issues in Modeling Psychopathology. Kluwer Academic Publishers: Boston, MA. pp 113-142.

Davis M, Whalen PJ (2001). The amygdala: vigilance and emotion. Mol Psychiatr 6: 13-34.

De Kloet ER, Wallach G, McEwen BS (1975). Differences in corticosterone and dexamthasone binding to rat brain and pituitary. Endocrinology 96: 598-609.

Delamater AR (2004). Experimental extinctin in Pavlovian conditioning : Behavioural and neuroscience perspectives. Q J Exp Psychol 57B: 97-132.

Erickson K, Drevets W, Schulkin J (2003). Glucocorticoid regulation of diverse cognitive functins in normal and pathological emotional states. Neurosci Biobehav Rev 27: 233-246. 
Foa E (2000). Psychosocial treatment of posttraumatic stress disorder. J Clin Psychiatr 61: 43-48.

Fuxe K, Wikstrom AC, Okret S, Agnati LF, Harfstrand A, Yu ZY et al (1985). Mapping of glucocorticoid receptor immunoreactive neurons in the rat Tel- and diencephalon using a monoclonal antibody against rat liver glucocorticoid receptor. Endocrinology 117: $1803-1812$.

Fyer A (1998). Current approaches to etiology and pathophysiology of specific phobia. Biol Psychiatr 44: 1295-1304.

Gorman J, Kent J, Sullivan G, Coplan J (2000). Neuroanatomical hypothesis of panic disorder, revised. Am J Psychiatr 157: 493-505.

Herry C, Garcia R (2002). Prefrontal cortex long-term potentiation but not long-term deprssion, is associated with the maintenance of extinction of learned fear in mice. $J$ Neurosci 22: 577-583.

Korte SM (2001). Corticosteroids in relation to fear, anxiety and psychopathology. Neurosci Biobehav Rev 25: 117-142.

Korte SM, De Boer SF, De Kloet ER, Bohus B (1995). Anxiolyticlike effects of selective mineralocorticoid and glucocorticoid antagonists on fear-enhanced behavior in the elevated plusmaze. Psychoneuroendocrinology 20: 385-394.

LeDoux JE (2002). Emotion circuits in the brain. Annu Rev Neurosci 117: 341-349.

Lu KT, Walker DL, Davis M (2001). Mitogen-activated protein kinase cascade in the basolateral nucleus of amygdala is involved in extinction of fear-potentiated startle. J Neurosci 21: RC162:1-RC162:5.

Lyons DM, Wang OJ, Lindley SE, Levine S, Kalin NH, Schatzberg AF (1999). Separation induced changes in squirrel monkey hypothalamic-pituitary-adrenal physiology resemble aspects of hypercortisolism in humans. Psychoneuroendocrinology 24: 131-142.

Maren S (2001). Neurobiology of Pavlovian fear conditioning. Annu Rev Neurosci 24: 897-931.

Meijer OC, De Lange ECM, Breimer DD, De Boer AG, Workel JO, De Kloet ER (1998). Penetration of dexamethasone into brain glucocorticoid targets is enhanced in mdr1A P-glycoprotein knockout mice. Endocrinology 139: 1789-1793.

Morgan CA, Grillon C, Southwick SM, Davis M, Charney DS (1995). Fear-potentiated startle in posttraumatic stress disorder. Biol Psychiatr 38: 378-385.

Myers KM, Davis M (2002). Behavioral and neural analysis of extinction. Neuron 36: 567-584.

Paxinos G, Watson C (1997). The Rat Brain in Stereotaxic Coordinates. Academic Press: New York.

Pugh CR, Fleshner M, Rudy JW (1997a). Type II glucocorticoid receptor antagonists impair contextual but not auditory-gue fear conditioning in juvenile rats. Neurobio Learn Mem 67: 75-79.

Pugh CR, Tremlay D, Fleshner M, Rudy JW (1997b). A selective role for corticosteone in contextual-fear conditioning. Behav Neurosci 111: 503-511.
Quirk GJ, Russo GK, Barron JL, Lebron K (2000). The role of ventromedial prefrontal cortex in the recovery of extinguished fear. J Neurosci 20: 6225-6231.

Rescorla RA (2001). Experimental extinction. In: Handbook of Contemporary Learning Theories. Erlbaum: Hillsdale, NJ. pp 119-154.

Richardson R, Ledgerwood L, Cranney J (2004). Facilitation of fear extinction by D-cycloserine: theoretical and clinical implications. Learn Mem 11: 510-516.

Roozendaal B (2003). Systems mediating acute glucocorticoid effects on memory consolidation and retrieval. Prog NeuroPsychopharmacol Biol Psychiatr 27: 1213-1223.

Roozendaal B, Bohus B, McGaugh JL (1996). Dose-dependent supression of adrenocortical activity with metyrapone: effects on emotion and memory. Psychoneuroendocrinology 21: 681-693.

Roozendaal B, Griffith QK, Buranday J, de Quervain DJF, McGaugh JL (2002). The hippocampus mediates glucocorticoid-induced impairment of spatial memory retrieval: dependence on the basolateral amygdala. Proc Natl Acad Sci 100: 1328-1333.

Roozendaal B, McGaugh JL (1997). Glucocorticoid receptor agonist and antagonist administration into the basolateral but not central amygdala modulates memory storage. Neurobio Learn Mem 67: 176-179.

Schelling G, Kilger E, Roozendaal B, de Quervain DJF, Briegel J, Dagge A et al (2004). Stress doses of hydrocortisone, traumatic memories, and symptoms of posttraumatic stress disorder in patients after cardiac surgery: a randomized study. Biol Psychiatr 55: 627-633.

Sotres-Bayon F, Bush DEA, LeDoux JE (2004). Emotional perseveration: an updated on prefrontal-amygdala interactions in fear extinction. Learn Mem 11: 525-535.

Takahashi LK (1994a). Organizing action of corticosterone on the development of behavioral inhibition in the preweanling rat. Dev Brain Res 81: 121-127.

Takahashi LK (1994b). Stimulus control of behavioral inhibition in the preweanling rat. Physiol Behav 55: 717-721.

Van Eekelen JAM, Kiss JZ, Westphal HM, De Kloet ER (1987). Immunocytochemical study on the intracellular localization of the type 2 glucocorticoid receptor in the rat brain. Brain Res 436: $120-128$.

Vianna MR, Szapiro G, McGaugh JL, Medina JH, Izquierdo I (2001). Retrieval of memory for fear-motivated training initates extinction requiring protein synthesis in the rat hippocampus. Proc Natl Acad Sci 98: 12251-12254.

Walker DL, Ressler KJ, Lu KT, Davis M (2002). Facilitation of conditined fear extinction by systemic administration or intraamygdala infusions of $\mathrm{D}$-cycloserine as assessed with fearpotentiated startle in rats. J Neurosci 22: 2343-2351.

Yehuda R, Golier JA, Halligan SL, Meaney M, Bierer LM (2004). The ACTH response to dexamethasone in PTSD. Am J Psychiatr 161: 1397-1403.

Zarate R, Agras W (1994). Psychosocial treatment of phobia and panic disorders. Psychiatry 57: 133-141. 